\title{
Hyperglycemia in Cancer Survivors: From Diagnosis through Survivorship
}

\section{Siviero-Miachon AA ${ }^{1}$, Spinola-Castro AM $^{1 *}$ and Guerra-Junior $\mathbf{G}^{2}$}

${ }^{1}$ Federal University of Sao Paulo - UNIFESP/EPM, Department of Pediatrics, Division of Pediatric Endocrinology, Sao Paulo, Brazil

${ }^{2}$ University of Campinas - UNICAMP, Faculty of Medical Sciences, Department of Pediatrics, Division of Pediatric Endocrinology, Campinas, Brazil

The tremendous improvement in survival of children diagnosed with cancer has resulted in a growing population that experiences longterm endocrine complications, such as growth impairment, weight gain or traits of the so-called Metabolic syndrome (MetS), which are well-known adverse effects and related not only to the disease and specific therapy used, but may also be determined by individual host characteristics. Glucose alterations are one of the components of the MetS and Insulin Resistance (IR) is a main condition that links all the other traits [1-3].

Nonetheless, short-term endocrine adverse effects, comprising transient hyperglycemia at diagnosis or during cancer treatment protocols, should also call our attention to their potential influence upon morbidity, as these patients may face increased risk for complicated infections, increased mortality, and disease recurrence [4-6].

Transient hyperglycemia is a quite different aspect of glucose metabolism disorder affecting patients with cancer and to date is very little understood [4]. Currently, transient hyperglycemia has been frequently described as an acute adverse event during induction chemotherapy, especially for Acute Lymphocytic Leukemia (ALL), either in adults or children [4-6].

L-asparaginase, an enzyme with established anti leukemic activity, seems to exert a direct toxic effect on pancreatic $\beta$-cell via inhibition of insulin production and release, or indirectly via induction of pancreatitis, resulting in hyperglycemia [7]. However, the incidence of L-asparaginase-associated pancreatitis does not explain the development of transient hyperglycemia in all studied populations [4]. Corticosteroids, either dexamethasone or prednisone, may also produce glucose changes and IR. The single effect of each drug (L-asparaginase or glucocorticoid) does not explain all the hyperglycemic episodes. Notwithstanding, transient hyperglycemia during ALL induction chemotherapy may probably result from the synergistic effect of both L-asparaginase and glucocorticoid, or from insulin deficiency due to inadequate secretion or action. Moreover, it is possible that leukemia per is may alter glucose metabolism and hyperglycemia may have an influence upon leukemic cell proliferation [4-6]. Chemotherapyinduced hyperglycemia also depends on genetic predisposition that could be triggered not only by weight gain, but also by ethnic factors, female sex, Down syndrome, puberty, and by the severity of the disease itself $[4,6]$.

The majority of ALL patients who developed therapy-induced hyperglycemia recovered when L-asparaginase and glucocorticoid were discontinued, and needed transient insulin administration during this period [4]. However, pancreatic $\beta$-cell function damage may occur in specific cases, and hyperglycemia may persist after therapy withdrawal. The mechanism responsible for this alteration is not completely understood yet $[4,8]$.

On the other hand, hyperinsulinemia and its resulting metabolic abnormalities, as well as impaired pancreatic $\beta$-cell dysfunction, including Diabetes Mellitus (DM) itself, have been reported in longterm survivors of childhood cancer [2,8-10]. In these individuals, Cardiovascular Disease (CVD) is a common severe late effect that can occur as a consequence of direct damage of treatment itself or secondary to accelerated atherosclerosis due to treatment-related cardiovascular risk factors [3].
Post-cancer treatment survivors present with increased cardiovascular risk factors, with epidemiological evidence for manifest CVD early in adult life, but after 30 years of age, according to a statement developed by the American Heart Association along with the Council for Cardiovascular Disease in the Young, based on the study of several pediatric states and their risk for CVD $[3,11]$. The mechanisms behind this are not clarified yet. Not with standing, there is a strong possibility that some pathways, different from those in noncancer populations, may be activated in childhood cancer survivors, underlying mechanisms for weight gain and IR. These include various hormonal deficiencies, damage of non hormonal systems, changes on insulin sensitivity, lipid metabolism, inflammatory mediators and adipokines, as well as reduced physical activity, which may be altered by various cancer therapies $[3,11]$.

Total Body Irradiation (TBI), untreated hypogonadism and abdominal adiposity (a feature related to cranial radiation therapy) were considered risk factors for the development of hyperinsulinemia, impaired glucose tolerance and type $2 \mathrm{DM}$ in pubertal and adult survivors of bone marrow transplantation (BMT), having TBI the strongest association [9]. To date, TBI as a preparative therapy for BMT is the key role in the genesis of IR, as stated by a large multicenter study that included survivors of both pediatric and adult BMT. The risk of developing type $2 \mathrm{DM}$ was three times as likely to occur in BMT recipients as in a control group, and this risk was associated with TBI [11]. Nonetheless, the mechanisms underlying this still remain unclear. TBI has been shown to alter mitochondrial function in muscle, liver, and pancreas, resulting in the development of IR, and type 2 DM. Other mechanisms related to the immunologic and inflammatory effects of BMT may play a role in the development of such features $[9,11]$.

Thus far, a statement has reported an increased incidence of selfreported DM in childhood cancer survivors, including 8,599 survivors in the Childhood Cancer Survivor Study (CCSS), a retrospectively ascertained North American cohort of long-term survivors who were diagnosed between 1970 and 1986, compared to 2,936 randomly selected siblings of the survivors. It was associated to TBI or abdominal irradiation [12]. A recent retrospective cohort study from centers in France and in the UK also highlighted a dose-response relation between radiation exposure of the pancreas and subsequent risk of diabetes on 2,520 questionnaires of cancer survivors. Unfortunately, there was no further clinical or hormonal profile (adiposity indexes, insulin or IR indexes), but just a self-declaration of diabetes, confirmed by contacting the patients' medical doctors $[13,14]$.

*Corresponding author: Spinola-Castro AM, Department of Pediatrics, 307 Doutor Diogo de Faria Street, Sao Paulo, Brazil, 04037-000, Tel: + 5511 55391093; Fax: + 5511 5579-9409; E-mail: aspinola.dped@epm.br

Received January 02, 2014; Accepted January 02, 2014; Published January 13 , 2014

Citation: Siviero-Miachon AA, Spinola-Castro AM, Guerra-Junior G (2013) Hyperglycemia in Cancer Survivors: From Diagnosis through Survivorship. J Metabolic Synd 3: e109. doi:10.4172/2167-0943.1000e109

Copyright: ( 2013 Siviero-Miachon AA, et al. This is an open-access article distributed under the terms of the Creative Commons Attribution License, which permits unrestricted use, distribution, and reproduction in any medium, provided the original author and source are credited. 
In summary, cancer and glucose metabolism disorders are strongly correlated. So far, it is well determined that children with cancer are candidates to develop MetS due to diverse causes. Hyperglycemia is one of the components of the MetS, and IR is the major mechanism leading to MetS, which in turn increases the atherosclerotic process and aggravates CVD that frequently affects cancer survivors. Currently, as the probability of survival for childhood cancer is increased, the development of MetS should be prevented, as well as the short-term complication regarding glucose metabolism disorders during cancer therapy.

\section{Reference}

1. Bhatia S, Landier W (2005) Evaluating survivors of pediatric cancer. Cancer J 11: $340-354$

2. Spinola-Castro AM, Siviero-Miachon AA, Guerra-Junior G, Geloneze B (2009) Insulin resistance in childhood cancer survivors: a link between metabolic syndrome features. In: Yao EB (Edr) Insulin resistance: new research. (1stedn.), Nova Science Publishers, New York, USA, PP: 235-251.

3. Siviero-Miachon AA, Spinola-Castro AM, Guerra-Junior G (2008) Detection of metabolic syndrome features among childhood cancer survivors: A target to prevent disease. Vasc Health Risk Manag 4: 825-836.

4. Spinola-Castro AM, Siviero-Miachon AA, Andreoni S, Tosta-Hernandez PD, Macedo CR (2009) Transient hyperglycemia during childhood acute lymphocytic leukemia chemotherapy: an old event revisited. Clin Adv Hematol Oncol 7: 465-472.

5. Sonabend RY, McKay SV, Okcu MF, Yan J, Haymond MW, et al. (2009) Hyperglycemia during induction therapy is associated with poorer survival in children with acute lymphocytic leukemia. J Pediatr 155: 73-78.

6. Baillargeon J, Langevin AM, Mullins J, Ferry RJ Jr, DeAngulo G, et al. (2005) Transient hyperglycemia in Hispanic children with acute lymphoblastic leukemia. Pediatr Blood Cancer 45: 960-963.
7. Knoderer HM, Robarge J, Flockhart DA (2007) Predicting asparaginaseassociated pancreatitis. Pediatr Blood Cancer 49: 634-639.

8. Mohn A, Di Marzio A, Capanna R, Fioritoni G, Chiarelli F (2004) Persistence of impaired pancreatic beta-cell function in children treated for acute lymphoblastic leukaemia. Lancet 363: 127-128.

9. Neville KA, Cohn RJ, Steinbeck KS, Johnston K, Walker JL (2006) Hyperinsulinemia, impaired glucose tolerance, and diabetes mellitus in survivors of childhood cancer: prevalence and risk factors. J Clin Endocrinol Metab 91: 4401-4407.

10. Hoffmeister PA, Storer BE, Sanders JE (2004) Diabetes mellitus in long-term survivors of pediatric hematopoietic cell transplantation. J Pediatr Hematol Oncol 26: 81-90.

11. Kavey RE, Allada V, Daniels SR, Hayman LL, McCrindle BW, et al. (2006) Cardiovascular risk reduction in high-risk pediatric patients: a scientific statement from the American Heart Association Expert Panel on Population and Prevention Science; the Councils on Cardiovascular Disease in the Young Epidemiology and Prevention, Nutrition, Physical Activity and Metabolism, High Blood Pressure Research, Cardiovascular Nursing, and the Kidney in Heart Disease; and the Interdisciplinary Working Group on Quality of Care and Outcomes Research: endorsed by the American Academy of Pediatrics. Circulation 114: 2710-2738.

12. Baker KS, Ness KK, Steinberger J, Carter A, Francisco L (2007) Diabetes, hypertension, and cardiovascular events in survivors of hematopoietic cell transplantation: a report from the Bone Marrow Transplantation Survivor Study. Blood 109: 1765-1772.

13. Meacham LR, Sklar CA, Li S, Liu Q, Gimpel N, et al. (2009) Diabetes mellitus in long-term survivors of childhood cancer. Increased risk associated with radiation therapy: a report for the childhood cancer survivor study. Arch Intern Med 169: 1381-1388.

14. de Vathaire F, El-Fayech C, Ben Ayed FF, Haddy N, Guibout C, et al (2012) Radiation dose to the pancreas and risk of diabetes mellitus in childhood cancer survivors: a retrospective cohort study. Lancet Oncol 13: 1002-1010. 